\title{
LEARNING THE LANGUAGE OF STATISTICS: CHALLENGES AND TEACHING APPROACHES
}

\author{
PETER K. DUNN \\ University of the Sunshine Coast \\ pdunn2@usc.edu.au \\ MICHAEL D. CAREY \\ University of the Sunshine Coast \\ mcarey@usc.edu.au \\ ALICE M. RICHARDSON \\ University of Canberra \\ Alice.Richardson@canberra.edu.au \\ CHRISTINE MCDONALD \\ University of Southern Queensland \\ Christine.McDonald@usq.edu.au
}

\begin{abstract}
Learning statistics requires learning the language of statistics. Statistics draws upon words from general English, mathematical English, discipline-specific English and words used primarily in statistics. This leads to many linguistic challenges in teaching statistics and the way in which the language is used in statistics creates an extra layer of challenge. This paper identifies several challenges in teaching statistics related to language. Some implications for the effective learning and teaching of statistics are raised and methods to help students overcome these linguistic challenges are suggested.
\end{abstract}

Keywords: Statistics education research; Undergraduate students; Discipline language; Teaching practice

\section{INTRODUCTION}

Learning a new subject requires learning its associated language. Leung states that using this language can be interpreted as a sign of expertise and mastery of concepts in the discipline (a positive interpretation), or as unnecessary jargon (a negative interpretation). The positive interpretation is "usually associated with the idea that knowing technical language is part of having technical knowledge and expertise" (p. 217). The need for technical terms to communicate complex concepts is evident even in subject areas not traditionally associated with language, such as mathematics and statistics. Indeed, "communication is at the heart of statistics" (Rangecroft, 2002, p. 34). Further, the American Statistical Association's Guidelines for Assessment and Instruction in Statistics Education (GAISE) committee made six recommendations for introductory statistics courses, one of which is to emphasise statistical literacy. They define statistical literacy as "understanding the basic language of statistics (for example, knowing what statistical terms

Statistics Education Research Journal, 15(1), 8-27, http://iase-web.org/Publications.php?p=SERJ

C) International Association for Statistical Education (IASE/ISI), May, 2016 
and symbols mean and being able to read statistical graphs) and fundamental ideas of statistics”. (Aliaga et al., 2005, p. 14)

The need to understand the language of any topic of study is clear, as illustrated by this excerpt:

Many students do not realize the importance of learning the technical language of what they are studying... Otherwise, how can you understand what you read in this book, or what your professor is saying? These technical words are necessary for efficient communication (Dossey, Otto, Spence \& Vanden Eynden, 2002, p. xv).

The true literacy demand of a new topic is much greater than just learning new words and their meaning (Schmitt, 2008). Mastering a new topic requires understanding and appropriately using the language of the discipline (through listening, reading, writing, and speaking). Teaching statistics, however, often focuses on the quantitative aspects (as reflected in the types of textbook exercises). Although these quantitative aspects are important, students may not completely understand the concepts in these problems at a deeper conceptual level if they do not understand the language surrounding them.

Performing arithmetic computations in statistics without engaging with the associated statistical concepts merely involves knowing how (activating procedural memory) in preference to knowing that (activating declarative memory). Sanz and Morgan-Short (2005) discuss that declarative memory is memory of facts and events, and refers to those memories that can be consciously recalled (or declared). Declarative memory can be further subdivided into episodic memory and semantic memory. Episodic memory represents our memory of personal experiences and specific events in time in a serial form. Semantic memory involves the acquisition of facts, meanings, knowledge, concepts, and associated vocabulary (Kutas \& Federmeier, 2000). This would suggest that declarative, semantic memory needs to be activated by the learner in order to develop deep understanding of statistical concepts.

One standard metric in vocabulary knowledge testing in the field of language teaching is the ability to use a word correctly in spoken and written contexts. The ability to define a word or term is less demonstrative of knowledge, as it only references surface knowledge of what a word means, not necessarily the deeper knowledge of the concept itself (Schmitt, 2008). As a scaffold for introductory learning, however, definitions are very useful, so the language of any topic being studied should be well-defined:

So what is a definition? It is putting a meaning to a word or a term. Why do we want to define? It is for efficient communication. How do we decide to define? When we want to formalize a concept or when we want to extend a notion along a logical imperative. (Guan \& Hoong, 2012, p. 30)

Unfortunately, as we will show, the language of statistics is far from being standardized. Studies show that the language used in mathematics and statistics contributes to the challenges faced by students in those disciplines (Shuard \& Rothery, 1984; Leavy, Hannigan, \& Fitzmaurice, 2013). We believe these challenges may impact students' learning in many aspects of an introductory statistics course:

1. Content: Students may fail to understand the content in written form (textbooks, readings, lecture notes) or in spoken form (lectures, videos, screencasts).

2. Participation: Students may struggle to participate in tutorial or discussion forum conversations.

3. Assessment: Students may fail to understand the instructions for assessment, fail to understand marking rubrics for assessments, or fail to complete assessment items correctly.

4. Feedback: Students may not understand the feedback provided on an assessment. 
5. Seeking assistance: Students may not be able to articulate needed assistance.

6. Group work: Students may struggle with group work (in class, or as part of assessment) if they lack the vocabulary to converse with others.

These linguistic challenges can contribute to statistics anxiety, the tendency "to equate learning statistics with learning another language” (Onwuegbuzie, 2000, p. 324) or "statisticophobia" (Summers, Waigandt, \& Whittaker, 2005; Sutarso, 1992), which in turn can lead to lower grades (Fullerton \& Umphrey, 2002; Sutarso, 1992). These negative attitudes can stay with students throughout their studies, and students who study further statistics subjects may learn by using surface-level strategies because they do not perceive statistics as useful or meaningful (Gordon, 1999). Not understanding discipline-specific concepts is also known to reduce student retention (Willcoxson, Cotter \& Joy, 2011). In summary, not understanding the language of statistics can manifest in many forms and have detrimental impact upon student learning in many different ways.

An important distinction to make is that international students who are "English as an additional language speakers" (EALs) do not learn new vocabulary in the same way as native English speakers. EALs rarely construct the extensive network of associations between words and their meanings necessary for fluent word association to the extent that native speakers do (Meara, 1978; Schmitt, 1998; Schmitt \& Meara, 1997; Zhang, 2003). This might seem to suggest that EALs would have greater difficulty when they meet new terms within statistics, but the opposite is more likely. This is because EALs tend to rely more on knowledge of the morphological form of new words to associate them with meaning, rather than on a pre-established network of word-meaning associations (Jiang, 2000). EALs are therefore less likely to think they know the meaning of new terms, or familiar terms used in a novel way, because they are in the habit of not trusting their own semantic networks to make a fully informed guess. Therefore, it follows that EALs may more readily consult a dictionary or ask for guidance, whereas native speakers would rely on their pre-existing semantic network and would assume their guess of the meaning from context is correct.

The first step towards helping students engage with and master the language of statistics is for teachers to be aware of, and understand, the variety of linguistic challenges that students can encounter. Six categories of words used in statistics have been identified (Rangecroft, 2002; Shuard \& Rothery, 1984): (1) words with the same meaning in mathematical English (ME) and general English (GE; Rangecroft uses the phrase "Ordinary English" but we prefer the term used in linguistics); (2) words which have meaning only in ME; (3) words with a meaning only in statistical English (SE); (4) words with different meaning in GE and ME; (5) words with a different meaning in GE and SE; and (6) words with a different meaning in ME and SE. Later, we consider the interaction between GE, SE, ME as well as English used in disciplines that use statistics.

In this paper, we study linguistic challenges faced by students studying statistics, including challenges involving symbols and notation, because, as Bock, Velleman, \& De Veaux (2010) note, these are part of the language of statistics. Sometimes, the linguistic term lexical unit (Arnaud \& Savignon, 1997) is used to refer collectively to groups of collocated words, individual words, and symbols. First, we discuss challenges created by the language used in statistics (Section 2), followed by challenges created by how the language is used (Section 3). We then make some comments and discuss suggestions for instructors to help students overcome these challenges (Section 4). 


\section{CHALLENGES CREATED BY THE LANGUAGE USED IN STATISTICS}

Communication in statistics involves using words from different sources ("fields"). Statistical language is a meld of general English (GE), mathematical English (ME), and English words used primarily in statistics, or statistical English (SE). In addition, because statistics is often taught as a service course for students from other disciplines, statistics also draws upon the English used in the discipline in which statistics is applied and in which the results must be interpreted, which we call discipline-specific English (DE). Since statistics draws upon these four different fields, words used in statistics may belong to more than one of these categories and consequently may be confusing for students.

\subsection{WORDS TAKEN FROM GENERAL ENGLISH}

In any discipline, communication relies on words from GE. In statistics, many GE words exist that retain their GE meaning(s), but some GE words are also SE words.

Some words used in statistics have a more specific meaning in statistics than in GE. Familiar words with a different, technical meaning are called "lexically ambiguous" (Kaplan, Fisher, \& Rogness, 2009) and have been studied in statistics by, among others, Kaplan et al. (2009; 2010), and Richardson, Dunn, and Hutchins (2013a). Kaplan et al. (2009) list 36 lexically ambiguous words used in statistics, including significant, power, control, random, and confidence. Studies show that students often struggle to learn the technical definitions of lexically ambiguous words and often retain the GE definitions of these words (Kaplan et al., 2009, 2010; Richardson et al., 2013a).

Lexically ambiguous words have the potential to cause problems for students' understanding as the students are familiar with the GE meaning(s) of the words and have to differentiate this meaning from the SE meaning when the words are used in a technical context. Furthermore, most students rarely engage with the language of statistics outside universities (Thompson \& Rubenstein, 2000) and hence do not become familiar with the SE meaning unless using the language in a statistics class.

The first step in helping students understand technical definitions of statistical words that have GE meanings is to identify which GE words have technical definitions. Kaplan et al. (2010) suggested avoiding GE words if possible, and introducing specific words for technical concepts, though such words may not be available for every concept. For example, Kaplan et al. (2009) suggested avoiding spread to describe the amount of variation in a set of data because spread has many other meanings. Kaplan, Rogness, and Fisher (2012, p. 4) suggested using variability in place of spread, as it "strikes a balance between being neither too familiar nor too technical a word to describe the concept it describes”. However, some popular statistics textbooks (e.g., Bock et al., 2010) use spread.

Communication in statistics naturally uses many GE words, but the potential for difficulties is that students do not know that GE words they encounter in statistics context have an SE meaning distinct from their GE perception. For example, significance has a technical definition in SE, but substantial does not (Wood, 1990). How is a student to know that only the former has a technical definition?

Students need to know that specific SE words have an overlap with GE and that they have to be careful not to confuse meanings. Many textbooks flag new words using highlighting, marginal notes, a change of font, an end-of-chapter list of new words, or hyperlinks in online resources; other words are assumed to retain their usual GE meanings. In most cases, such words are flagged only in their first appearance, and only three from a selection of 30 textbooks reviewed by the authors had an end-of-book glossary of terms. 
Such a glossary could provide students with a single, compiled list of GE words with SE meanings (and by implication, GE words retaining their GE meaning).

\subsection{WORDS USED PRIMARILY IN STATISTICS}

As with any discipline, statistics uses many words that do not come from GE, ME or DE that will be new to students. These words are used primarily within the statistics context, and rarely outside that context. Such words that are rare and isolated to a particular context of usage are referred to in linguistics as "marked," in line with markedness theory (Richards \& Schmidt, 2010). Words that are common and regularly occurring are "unmarked.” In the social sciences more broadly, markedness is used to distinguish two meanings of the same term, where one is common usage (unmarked sense) and the other is specialized to a particular context (marked sense). For instance, standard error is marked as it is a specialized term peculiar to statistics, whereas significant is unmarked as it occurs commonly. The terms "marked" and "unmarked" are used in the following discussion of the meanings of statistical terms to set the discussion in this theoretical framework of markedness developed in linguistics.

Statistical concepts associated with GE words Some simple statistical concepts may be understood by students, but they may not know the word to associate with that concept. The associated word is often an unmarked GE word with a statistical meaning that the student does not know. This means that students actually have the statistical knowledge, but are not familiar with the language used to express that knowledge technically: "I know what I mean but I don't know how to say it." One example may be the word mode, a marked statistical word for the simple concept of the most frequently occurring value.

Often, an unmarked GE word may be used as a reference point to discuss a familiar concept, whereafter the marked SE word can be introduced. For example, a normal distribution may be introduced as a bell-shaped distribution. This also applies to symbols: students may know what a sample arithmetic mean is, but may not be familiar with the symbol $\bar{x}$ to represent this concept.

Without being explicitly taught these SE terms, students may understand the concept but have difficulty understanding technical words when reading or listening. Hence, students may not recognise that the text is referring to a concept that they actually understand. If the student did have mastery of the term, they would be able to read and listen, then comprehend, and by extension, successfully articulate the concept in writing and speaking.

In addition, different types of assessment create different consequences for students. An assessment piece based around reading or listening may cause some students to perform poorly, because they do not understand the language being used (not because they do not grasp the concept). Assessments, however, can also positively leverage this challenge by encouraging students to learn the appropriate language. A student attempting a written or spoken assessment piece may do well or may perform poorly, depending on how the assessment balances the understanding of concepts and the correct use of the technical terms to describe the concepts.

Statistical concepts associated with $S E$ words Statistical language includes technical words with technical meanings that are rarely used outside the context of statistics. Examples of marked words with technical meaning include ANOVA, boxplot, and heteroscedasticity. Statistics also contains numerous new symbols that students need to learn that express new concepts (such as $\sigma$ for a population standard deviation, or $\rho$ for a 
population correlation coefficient). Some students will encounter Greek letters for the first time while others will be unfamiliar even with mathematical symbols such as \pm .

In some ways, these words and symbols are easier to teach than the others so far discussed: There are no prior expectations of a word's meaning that need to be unlearnt, and students are presented with a new technical word to express a new technical concept simultaneously.

\subsection{WORDS TAKEN FROM MATHEMATICAL ENGLISH}

Students who study introductory statistics generally have studied some mathematics at school. This means they have some exposure to lexical units with mathematical meaning (Rangecroft, 2002), such as equation and square root. Unfortunately, some ME lexical units have a subtly different meaning in SE.

For example, Rangecroft identifies the word estimate. In mathematics, students may be asked to estimate a distance, or to estimate the answer to a computation, when the student is being asked to make a reasonable guess. In statistics, the word estimate may also be used this way (for example, "Estimate the percentage of each slice in this pie chart"), but more commonly to estimate in statistics requires a mathematical calculation. For example, a student may be asked to "Estimate the population mean diameter of a pizza based on these 40 observations" and the correct answer is the calculated sample mean. A student answer consisting of a reasonable guess would usually be deemed incorrect. Thus, in ME and in $\mathrm{GE}$, to estimate means to make a reasonable guess, but in SE to estimate generally means to provide "a numerical value for a population parameter on the basis of information collected from a sample” (Everitt, 2006, p. 143).

Graph is another word with different meanings in ME and SE. In ME, a graph generally shows the deterministic relationship between two variables (such as the graph of $y=x^{3}+$ 1 ), whereas a graph in statistics generally displays data or a non-deterministic relationship between random variables.

The word significant also presents a similar problem (Rangecroft, 2002). In GE, significant usually means "substantial" or "important", but in ME significant is used in the context of significant figures with a different meaning (akin to "level of accuracy"). In SE, significant has yet another meaning. Likewise, a variable in mathematics can mean a fixed value in an equation such as $2 x+1=7$, whereas variable in statistics usually means a random variable.

This issue also happens with symbols. For example, some authors (such as Zieffler \& Catalysts for Change, 2013) represent a population proportion using $\pi$, hence Greek letters are used consistently for population quantities ( $\mu, \sigma$, and $\rho$, for example) and English letters for corresponding sample quantities (respectively, $\bar{x}$, $s$, and $r$ ). However, this notation may confuse students who are familiar with $\pi$ representing the ratio of a circle's circumference to its diameter.

\subsection{DISCIPLINE-SPECIFIC TERMS}

Introductory statistics courses often enrol students from many disciplines. As a result, some words, terms and symbols used in statistics may have a different meaning in the student's home discipline. This creates challenges with using the term in statistics, because (a) students generally identify with their home disciplines and so the meaning of the word in the home discipline has more relevance and importance to them, (b) the students will study more subjects within their home disciplines than in statistics, and (c) statistical results are usually interpreted in the context of a discipline using DE. As a result, the statistical 
meaning may be missed, and the meaning from the home discipline inappropriately used (Anderson-Cook, 2010). In addition, Richardson, Dunn and Hutchins (2013b) found the tutor had a statistically significant effect on students' ability to define a lexically ambiguous word in statistics. The discipline backgrounds of the tutors may be part of the explanation for confusion between and DE and SE meaning of certain terms.

One example is the word sample. In statistics, a sample is a set of observations drawn from a population. In business, however, a sample is a free small quantity of product and in biomedicine a sample is a single specimen (of blood, urine, etc.) rather than a set of observations. This may be why the authors have heard first-year students incorrectly state "I have taken 40 samples" rather than "I have taken one sample of 40 observations". Other examples include blocking (with different meanings in psychology and biology) and regression (with different meanings in psychology and medicine). Anderson-Cook identifies and discusses other examples, such as design, parameters, model, analysis, and factor.

Symbols from a student's home discipline may appear in statistics with different meanings also. For example, $\rho$ is often used for density or resistivity, $\alpha$ for angular velocity, and $\beta$ for beta-radiation and describing turns in proteins in biochemistry.

\section{CHALLENGES FROM CONTEXTUAL USE OF WORDS IN STATISTICS}

The previous section noted the challenge of many different word fields used in statistics. Further to this, the way these words are used in context in statistics discourse may create additional challenges.

\subsection{STATISTICAL PHRASES BUILT FROM GENERAL ENGLISH WORDS}

Challenges may arise when lexical units consist of familiar words, but the collocationof these familiar words creates a new phrase with a new, technical meaning. Some students may not be aware that the collocation of two familiar words creates a new lexical unit whose definition needs to be learnt. Consider confidence interval; most students would be familiar with the two GE words confidence and interval, but the lexical unit confidence interval has a technical meaning with which they may not be familiar. Another example is standard error, which is a difficult concept to understand (Garfield \& Ben-Zvi, 2008), made harder because it is not an "error" in the common use of the word (as a "mistake"), and nor is it "standard" in any common use of the word. Students need to learn that standard error must be used as a discrete lexical unit, and so cannot be further modified morphologically (for instance, non-standard error is never used), and that the individual familiar words do not point to the meaning. Furthermore, standard error could be used to refer to an error that is quite standard; for example:

...the program tries to determine whether the student has made a standard error, which occurs often in students' solutions (for example, changing all signs when reversing signs...) (Issakova, 2006, p. 4, emphasis added)

Other lexical units in this category include degrees of freedom and central limit theorem. Of course, the individual words in some lexical units may assist in the prediction of meaning (such as alternative hypothesis), but the lexical unit usually has a more technical, specific meaning than what might be predicted from the collocation of the individual words.

Some statistical symbols could be considered as a lexical unit also, such as $s_{\bar{x}}$, which is commonly used to represent the standard error of the mean. The combining of the 
symbols for standard deviation and mean produces a symbol that does not represent a mean, and is not the standard deviation of any data.

\subsection{MULTIPLE WORDS FOR ONE CONCEPT}

The genesis of statistics is in many disciplines (often independently and concurrently), and so statistics includes examples of different words being used for one concept. For example, the $x$-variable in regression has been called a regressor, covariate, predictor, independent variable, and explanatory variable, to name a few. An expert may switch among these depending on the purpose of the method, but a student still learning the concept as well as the terminology can become confused. The confusion can be manifest when the instructor teaches one of these terms in classes, but different terms appear in readings associated with the course (perhaps taken from different texts), the software used with the course (Section 3.6), videos, test banks and online quizzes from third parties, research papers that the students are required to read, library books, and similar external resources that students consult.

If the language is different across these resources, students may not even realise the same concept is being referred to in the different resources. Instructors may not even recognise that different terms are being used because of their familiarity with the synonyms. Two situations that may lead to this are when the textbook changes and instructors continue to use the language from the previous textbook (in lecture slides, for example), or when a tutor's home discipline uses a particular term differing from that used in the course. In addition, large courses with many teaching staff may have different staff members using different terms (perhaps without even realising). Furthermore, students who have studied statistics before may encounter a synonym for a term they know but do not immediately recognise that the new word represents a familiar concept.

This issue of multiplicity also presents a challenge with symbols and notation. For example, the population intercept in a regression model can be labelled as $\alpha$ or as $\beta_{0}$, which are different from the intercept of a linear equation presented in mathematics (for example, $y=m x+c$, when the intercept is $c$ ). Regression lines may be referred to as lines of best fit, least-squares regression lines, or just regression lines.

Similarly, the sample mean is usually represented as $\bar{x}$ but some texts use $M$ (Aron, Aron, \& Coups, 2009). One author has taught with the Bock et al. (2010) text that denotes the sample mean as $\bar{y}$ (on reasonable grounds, justified on page 58 of the text). Every student, however, had a calculator that calculated the sample mean using the key labelled $\bar{x}$. On calculators that did have a key for $\bar{y}$, that key computed the mean of the second variable for bivariate data. Calculators may have even more variety for symbols. Symbols used for the sample standard deviation include $x \sigma n-1$ (HP SmartCalc 300s, Casio fx82TL), $s_{x}$ (TI83/84), and $s x$ (Casio fx82 AU PLUS, Sharp EL531 range), for example.

A student's mastery of a concept may not take place in one introductory course. This is especially an issue when teaching statistics to students from non-statistical disciplines, where the term commonly-used for a concept differs across the disciplines being taught. An interesting example of this issue appears in the current Australian mathematics senior secondary curriculum (Marshman, Dunn, McDougall, \& Wiegand, 2015). In some places, independent variable is used in Essential mathematics, Unit 3 topic 4 of ACARA (2014a), but explanatory variable is used in General mathematics, Unit 3 topic 1 of ACARA (2014b) for the same concept.

Google ngrams (books.google.com/ngrams) provide a simple corpus search to explore changing trends in language choice (Figure 1) by analysing the longitudinal frequency of terms used in books indexed by Google Books. The use of independent variable has been 
decreasing since about 1975, though the use of explanatory variable and regressor have remained steady since 1990, and covariate may be gaining ground. Stem-and-leaf plot was very popular initially, but now is used less often than stem plot.



Figure 1. Longitudinal (through 2008) percentage of occurrence of selected statistics terms in the Google Books Ngram Corpus. Figure taken from the Google ngram viewer.

\subsection{ONE TERM FOR MANY CONCEPTS}

The multidisciplinary evolution of statistics has led to some words having multiple meanings in statistics. Average may be the most well-known example, which has been used to refer to the mode, median, or to one of many types of mean (arithmetic mean, harmonic mean, geometric mean, trimmed mean, etc.). Another confusing example is independent, alluded to earlier. Even in the regression model context, independent has two meanings: the $x$-variables in regression are sometimes called the independent variables, but the entire set of $x$ (independent) variables may be independent of each other, or not. To further complicate matters, independent has another meaning in GE and yet another in ME.

A similar issue also happens with symbols and notation. For example, $p$ can represent a $p$-value or a population proportion; $\beta$ can represent a standardized regression coefficient, a population slope in a regression equation, or the probability of a Type II error in a test; $\alpha$ can represent a population intercept in a linear regression model, Cronbach's $\alpha$, or the probability of a Type I error.

\subsection{STANDARD ENGLISH WORDS WITH NO CONSENSUS DEFINITIONS}

Many words used in statistics are defined differently in different textbooks, and in most cases these differences are minimal and of little consequence. Sometimes, however, these 
differences are more important. If textbook writers cannot agree on a definition, should students be expected to be precise with their definitions?

For example, many statistics textbooks discuss lurking variables and confounding variables. Some authors consider the two terms as synonyms: "Confounding variables are also known as lurking variables" (Pfenning, 2011, p. 46). Sullivan (2010, p. 17) states that "Often, the cause of confounding is a lurking variable". MacGillivray, Utts, and Heckard (2014) define a confounding variable as a variable "that is not taken into account but is associated with an explanatory variable" (p. 52), but also notes later that sometimes these variables are called lurking variables, and instead confounding variables are used for situations where "we cannot distinguish between the effects" of two explanatory variables (p. 53). Utts and Heckard (2015) describe a lurking variable as a special case of a confounding variable that is not measured or considered in the interpretation of a study. Moore, Notz, and Fligner (2015) and Johnson and Kuby (2012) do not mention confounding variables but do mention lurking variables. Bock, Velleman, and De Veaux (2010) explicitly distinguish between them, and give different definitions for the two terms in a section entitled Lurking or Confounding? Flanagan-Hyde (2005) states that extraneous variables and lurking variables are synonyms, whereas confounding variables are different. Flanagan-Hyde also identifies many other modifiers of the noun variable, which further increases the potential for confusion.

There are other lexical units commonly used in introductory statistics that have disparate definitions, such as degrees of freedom (Eisenhauer, 2008, p. 75). Different authors use different definitions for discrete and continuous variables. Wild and Seber (2000) advise that:

the main criterion for deciding whether to treat a variable as discrete or continuous is whether the data on that variable contains a large number of different values that are seldom repeated or a relatively small number of distinct values that keep reappearing. Variables with few repeated values are treated as continuous. Variables with many repeated values are treated as discrete. (p. 41)

In contrast, Moore et al. (2015) describe discrete random variables as those "that have a finite list of possible outcomes" (p. 276). These two definitions can lead to different classifications, as the Petty (2014) blog discusses with this example (brackets added):

...the price of apps in the App store. There are only about twenty prices that can be charged - 0.99, 1.99, 2.99 etc. These are neither whole numbers, nor counts, but as you cannot have a price in between the given numbers, and there is only a small number of possibilities, this is best treated as discrete data [using the definition of Wild and Seber]. Conversely, the number of people attending a rock concert is a count, and you cannot get fractions of people. However, as there is a wide range of possible values, and it is unlikely that you will get exactly the same number of people at more than one concert, this data is actually continuous [using the definition of Wild and Seber].

Lexical units with disparate definitions are not restricted to introductory statistics. For an example from more advanced statistics, different definitions appear for random effects (Gelman, 2005; Kreft \& De Leeuw, 1998).

\subsection{PRONOUNCING WORDS}

Sometimes students know the correct word to use, can use it correctly, and may even understand the concept it represents, but do not pronounce the word correctly. For example, the authors have heard many students say outlier as "out-LEE-ah" or even as "outliner". When the standard pronunciation is not taught explicitly to students, communication issues may arise because when the word is pronounced incorrectly it may be incomprehensible. 
The word may not even be comprehensible when it is pronounced correctly because the standard pronunciation is unfamiliar to the listener. If assessment consists purely of reading and writing, this issue will remain undetected and students may continue to have this problem, and perhaps even be unaware of their pronunciation error.

Other common examples are for students to pronounce median as "medium" and $\chi$ as "chai" (the first syllable in "China") rather than "ki" (the first sound in kite). In addition, many native English-speaking students find some words quite tricky to pronounce anyway ("Kolmogorov" and "heteroscedasticity", for example). Evidence exists that speaking the words is associated with learning the statistical terms (Lavy \& Mashiach-Eizenberg, 2009), hence ensuring students practise speaking the words correctly is important.

\subsection{SOFTWARE-RELATED ISSUES}

Most statistics courses use statistical software. This has advantages (Ben-Zvi, 2000), but may add an additional cognitive burden on the student in terms of extra work and time spent learning to use the software: "There's always overhead in learning to use a tool itself before students can benefit from the tool for learning statistics.” (Chance, Ben-Zvi, Garfield, \& Medina, 2007, p. 8)

Another software-related challenge is that the language used in the software input and/or output may be different from the language used by the instructor and/or other course resources (Section 3.2). This alone can make teaching software difficult apart from actually teaching how to use the software itself. As one example, SPSS uses the lexical unit scale variable to describe a quantitative variable that could cover an interval or ratio variable.

Another example is that $\mathrm{R}$ ( $\mathrm{R}$ Core Team, 2014) uses the command barplot() to produce what is commonly called a barchart, though the command barchart() is a function in the lattice package in $\mathrm{R}$ (which must be loaded explicitly by the user). In addition, barplot() produces vertical bars by default, whereas barchart() produces horizontal bars by default, perhaps implying to some students that barcharts and barplots are different graphs. Another example of varied language occurs in SPSS: at least four ways exist to produce a linear regression model, and the language and output are not consistent amongst these ways nor with that used in logistic regression. The constant term appears in the model as either the intercept or the constant (and sometimes appears in the output at the top of the list of coefficients and sometimes at the bottom), the $y$-variable appears as the dependent or the target variable, and the $x$-variables appear as predictors, covariates or explanatory variables.

\subsection{STATISTICAL CONCEPTS IN GENERAL TERMS}

In introductory courses, the content is pitched at an introductory level to avoid complicating the subject matter. This may create challenges for students later in the course. For example, students may learn about "the" mean in class, only to read later about a specific type of mean (weighted mean, trimmed mean, arithmetic mean, harmonic mean, or geometric mean) and students may then not be sure which mean they were taught originally. This raises a question about whether the simple, but potentially confusing, word mean should be preferred over the more specific, but more cumbersome sample arithmetic mean. MacGillivray et al. (2014, p. 118) inform students:

...from a mathematical viewpoint, there is an arithmetic average and a geometric average, but the word 'average' on its own always refers to the arithmetic average (which is the total sum of the values divided by the number of values). In statistics, 'average' = 'sample mean' = 'data mean'. 
Another example is the use of correlation coefficient. Students may later encounter the term Spearman's correlation coefficient or Pearson's correlation coefficient and not be sure which type of correlation coefficient they were taught. Kaplan et al. (2012) suggest using specific terms to alleviate this issue, while sacrificing some simplicity.

In both of these examples, despite the potential complications, the general principle remains sound (all the means refer to some measure of central tendency; both correlation coefficients measure an association between two variables).

\section{TEACHING IMPLICATIONS}

In the previous two sections, a number of linguistic challenges that students may face in their study of statistics were identified. Is it important that students learn to use the correct terminology? The authors believe that the answer is "Yes"; if students are to engage with other professionals, read academic publications, produce research themselves, or even to be statistically educated in the sense of Aliaga et al. (2005), they need to be explicitly taught statistical terminology. Leung (2005) states that "it is important to wean pupils off everyday language and to use technical mathematics language in a planned and systematic way” (p. 127).

If engaging students with the language used in statistics is important, understanding both the language used in statistics and the way in which it is used, are important because:

Knowing that a problem exists is the first step to 'solving' it. If as teachers we can become more attuned to the possibilities of misunderstandings arising from language difficulties, we can perhaps recognize them and make the necessary explanations. (Rangecroft, 2002, p. 36)

With these challenges in mind, some considerations for teaching are now presented.

\subsection{CONSIDERATIONS FOR TEACHING}

Many of the language issues presented in this paper can be attributed to the natural diversity and evolution of language (Figure 1), which affects all discipline-specific terminology, including statistics terminology. So when statisticians refer to variant definitions of certain terms, or do not use a single term for a given concept, they are participating in the natural evolutionary process that language has always undergone as a product of humans' instinctive creative ability to fashion and reinterpret words and meanings over time (Pinker, 1999). The reality is that some language issues may never be resolved; for example, different disciplines have certain terminology entrenched, so changing the usage of this terminology would be difficult as human usage dictates attribution of meaning; style manuals, dictionaries and glossaries of terms are transitory records of current usage:

Language is not a protocol legislated by an authority but rather a wiki that pools the contributions of millions of writers and speakers, who ceaselessly bend the language to

their needs and who inexorably age, die, and get replaced by their children, who adapt the language in their turn (Pinker, 2014, p. 3).

Instructors cannot change the language embedded in statistical software, which will continue to reflect the variety in language that exists in statistics itself. Furthermore, the choice of language used in non-statistical disciplines is out of statisticians' control, so statistics instructors will need to work within these constraints.

Any student who engages with statistics will need to learn the language of statistics, and thus the student will need to overcome or manage these challenges. The question for 
instructors is therefore: What is the best way to teach the basic concepts of statistics with this in mind?

Guan and Hoong (2012) use two key principles to guide their use of definitions in secondary school mathematics that we adapt to statistics:

1. The statistics taught need not be presented with the degree of rigour required in advanced statistics.

2. The statistics taught should be faithful to the spirit of the method.

For example, instructors may decide not to provide the Welch-Satterthwaite equation for computing the degrees of freedom in a two-sample test of means, but just use the result of the calculation that appears in software output.

Ultimately, any solution depends on the main purpose of the statistics course. Instructors of a course that is the only statistics course that a student is required to take and whose main focus is foundational statistical principles will be less concerned about the specific language mastered. In contrast, an instructor of an introductory course that is a prerequisite to further statistics courses in a variety of disciplines, or whose main purpose is for students to be able to read and understand journal articles in a particular discipline, may need to focus more on some of the terminology.

Maintaining consistency in language across all the resources used within a single unit of study - the lecture material, the textbook, the software, any journal articles referenced, any readings from other texts, videos from the internet, and so on-is almost impossible.

In conclusion, some key considerations for instructors are:

1. Having students master one set of terms is better than having them master none at all, or confusing students with many terms.

2. So many challenges have been identified that a single solution, or even a small number of solutions, to address every challenge is unlikely to exist;

3. Not every challenge is of equal importance (mispronouncing $\chi$ is probably less concerning than not knowing which word to use to express an important statistical concept);

4. Not every challenge is likely to cause the same amount of confusion for students;

5. Some issues are more relevant to different communication modes (reading; writing; listening; speaking) than others;

6. Rangecroft (2002) observes that teachers often use GE and simple terms when speaking, while written text often uses more formal language with more use of SE;

7. Some terms have multiple linguistic challenges (such as significant and independent);

8. Some challenges are more relevant in some contexts than others (for example, medical students need only adopt terminology common in that field);

9. Many, if not all, of these linguistic challenges will never be resolved and hence the question for the instructor is how to manage these challenges for the greatest benefit of the students.

With these issues in mind, we synthesise and comment on some possible solutions to the issues described here.

\subsection{POSSIBLE SOLUTIONS}

Statistics instructors could develop solutions at any point on a continuum from pretending these linguistic challenges do not exist to completely embracing and teaching all facets of every issue. Neither extreme is probably helpful.

Some authors have attempted to address the issues discussed (for example, AndersonCook, 2010; Carlisle, Fleming, \& Gudbrandsen, 2000; Ellis, 1994; Kaplan et al., 2012; 
Lavy \& Mashiach-Eizenberg, 2009; Pitt 1991; Rangecroft, 2002; Rumsey, 2002), but in most cases these solutions (while appearing sensible) are not evidence-based. That is, although the problems may be identified reasonably well, many opportunities exist for evidence-based research into ways to help students with these linguistic challenges.

In this section, some of these insights, open research areas, and suggested solutions for some of these linguistic challenges are offered from the literature. We also make some observations and general suggestions based on the previous sections.

The implicit learning/explicit teaching continuum Two contrasting approaches for helping students acquire vocabulary are described in the literature: incidental learning, and explicit teaching (Carlisle, Fleming, \& Gudbrandsen, 2000; Ellis, 1994). Incidental learning takes place when learners are focused on comprehending meaning rather than on the explicit goal of learning new words. The approach holds that communicative use of new vocabulary through authentic tasks or action, such as solving a real-world problem or discussing the content of a research article, assists in concept formation and retention. In contrast, explicit teaching involves a deliberate focus on the teaching of terminology, either directly through activities such as matching terms to definitions, or indirectly, by having students teach each other the meanings of terms they find in sections of a reading (Willis \& Willis, 2007).

In support of an implicit learning approach, Rumsey (2002) suggested that instructors should not concern themselves too greatly about specific terms and their specific meaning in some situations:

Some ideas, such as "standard error" can take you a long way in a course, and are worth spending a great deal of time developing. Other terms, like "precision," "accuracy," "reliability," "bias," and "consistency" all sound the same to students. In my opinion, splitting hairs about these terms will only create confusion and frustration. My advice is to choose the most important ideas, and stick to them. (Rumsey, 2002, Section 3.5)

In an example of an explicit teaching approach, Kaplan et al. (2012) argue that specific statistical words should be chosen where possible, while acknowledging that sometimes this is not possible. Similarly, Anderson-Cook (2010) argues for a "careful introduction of new terminology, organizing glossaries and references", and one of Pitt's (1991) recommendations is to reinforce the precise use of language. Rangecroft (2002) acknowledges two contrasting approaches to manage conflicting definitions of terms: (1) explain everything in GE and avoid SE (and favour accessibility) or (2) always use a correct SE vocabulary (and favour precision). Rangecroft concludes that both approaches have drawbacks and merits, so no one answer exists. Lavy and Mashiach-Eizenberg (2009) suggest combining both approaches so "that students be presented with both their formal and informal definitions" of words (p. 7).

Managing synonyms In relation to the continuum from implicit learning to explicit teaching, which approach to use to teach synonyms requires special consideration. Providing students with a list of technical synonyms early on would seem to be counterproductive, overloading students with numerous terms for one concept before they even have the concept solidified. As a result, teachers may try to focus students on the concept and use one term to describe that concept while the concept is formative. Although exposing students to some common synonyms for statistical terms may seem important, an examination by the authors of over 30 common introductory statistics textbooks found that none of the textbooks presented a list of synonyms for concepts that can be described with multiple words. To introduce and use many synonyms when the concept is being learnt could distract students from learning the concept itself. That said, some textbooks do alert 
students to the possibility of one or two important synonyms in some cases: for instance, Utts and Heckard (2002) explicitly alert students to alternative terms response variable and dependent variable. Another example appears in Johnson and Kuby (2012), who present alternative notations for the alternative hypothesis $\left(H_{a}\right.$ and $\left.H_{1}\right)$.

Some reasons textbooks do not present a comprehensive list of synonyms may be that such a list would be long, contain many synonyms the student would never encounter, possibly be incomplete, and potentially increase confusion. For example, the word independent can be used to describe an explanatory variable in regression, as well as to describe whether a set of explanatory variables are related to each other or not, also in regression; explaining this could create more confusion than it clears.

Iterative learning One insight into how students develop word-meaning associations when encountering statistical terms is gained from Richardson et al. (2013a), who studied students' definitions of many lexically ambiguous, statistics-related words. At the start of semester, before any instruction, almost all (90.4\%) students in an introductory statistics class defined significant using the unmarked GE meaning of the word even when presented with the word in a statistical context. Later in the semester, after a period of instruction, an increased number of students tried to give a SE definition of the word (13.2\% in Week 1, compared with $25.7 \%$ in Week 13$)$, though most did not do so correctly (11.6\% in Week 1, compared with $20.5 \%$ in Week 13). In other words, over the semester many students came to realise the word significant had a special, technical meaning in statistics even if they could not always articulate that meaning well. This suggests that some students go through distinct phases of first recognising that a word has a technical meaning before they can actually articulate what that meaning is.

Embracing ambiguity Some instructors may respond to linguistic challenges by maintaining consistency in terminology throughout the course. Maintaining a consistent language in a course can be quite difficult, as statistical software and textbooks often use different language. In addition, whatever consistent language is adopted may be at odds with the language used in research papers the students will read or with the language used in the variety of home disciplines of the students. As a result, many instructors may decide to abandon this idea and instead embrace the linguistic challenges. This should not be interpreted as sacrificing the precision of statistical language:

...'fuzziness', ambiguity, multiplicity of meaning and exploratory discussion in everyday language should be recognised, not as failure to achieve a truly [statistical] degree of precision, but as essential to making [statistical] meaning and to learning [statistical] concepts (Barwell, Leung, Morgan, \& Street, 2005, pp. 144-145; references to "mathematics" replaced by "statistics").

This is the tension that instructors experience between "the held notion that [statistics] is, or should be, precise and the suggestion that [students] may learn [statistics] better when it is exploratory and ambiguous" (Barwell et al., p. 145; references to "mathematics" replaced by "statistics").

This approach of embracing the ambiguities is also supported elsewhere (Barwell, 2005; Leung, 2005). As Barwell (2005, p. 143) states: “the notion of 'ambiguity', come[s] to be seen instead as a resource, a resource implicitly exploited by the teacher and her students”. In this spirit, Lavy and Mashiach-Eizenberg (2009) suggest that (a) new terms be introduced in both their GE and SE meaning, then compared and contrasted; and (b) students should engage with the language through problems and exercises, emphasising the spoken language. 
Kaplan, Rogness and Fisher (2014) intentionally exploit the challenges to help students with the language issue; the context was the lexically-ambiguous word random, but the principles may apply to other lexical units also. Part of their strategy was to include examples of the use of the word random in a non-statistical manner to explicitly contrast the GE and SE definitions. Anderson-Cook (2010) suggests that students discuss their understanding of concepts using the technical statistical words and also without the use of statistical jargon. Anderson-Cook also suggests that a partial solution may be to predicate words with "statistically" when words are used in a statistical context (for example, "statistically significant" identifies the word "significant" as having a SE meaning and not a GE meaning).

Avoiding ambiguity Embracing ambiguity may be useful when words are being introduced to help students distinguish between SE and GE meanings. Afterwards, unnecessary ambiguities can be avoided by ensuring that terms from SE with GE meanings are avoided in the GE context when possible. For example, confusion can be avoided if the word significant is substituted with synonyms such as considerable, substantial, or large when used in a non-statistical context and significant is reserved to mean "statistically significant” (Miller, 2008).

Verbal interaction Lavy and Mashiach-Eizenberg (2009) note that "spoken language plays an important role in shaping how the informal statistical definitions taught in schools are remembered", suggesting that having students speak in the language of statistics with other students helps them grasp the language. This type of speaking activity is also a wellrecognised component of effective vocabulary acquisition and concept formation in language learning (Willis \& Willis, 2007), and an opportunity exists to evaluate the utility of this in the statistical context. Although Barwell (2005) is writing in the context of mathematics, his observation applies equally to statistics:

We have argued that doing and learning mathematics and 'doing' and learning language are social activities. Language is about more than words; mathematics is

about more than numbers. We have shown, furthermore, how a view of language as social practice is inseparable from a view of mathematics as social practice (p. 146).

Recursive learning Instructors can ensure that new words or phrases are introduced at the same time as the concept, and that the meaning is reinforced numerous times (Rohrer \& Taylor, 2006) by recycling vocabulary through multiple language-based activities (Schmitt, 2007) before students can be reasonably expected to associate the word with the concept. The same approach can be used for helping students learn common statistical acronyms (such as SE for standard error; IQR for interquartile range). Again, instructors may choose to use this strategy as part of a continuum of responses.

\section{CONCLUSION}

We have presented a range of teaching responses to a set of linguistic challenges in learning and teaching statistical concepts. Instructors need to realise that the choice of solutions depends on a variety of factors. Instructors need to be flexible in their choice of teaching methods and need to adapt to the various needs of learners, using a mixture of explicit and implicit strategies in a responsive manner. Students face a plethora of challenges students face in acquiring the concepts of statistics through the available language used in the discipline. We encourage textbook authors and developers to acknowledge this, and work towards ways of embracing these challenges without 
compromising the quantitative elements of statistics. A balance needs to be reached, however, between the mathematical and linguistic requirements of an introductory statistics course, and how an instructor balances these two depends greatly on the context.

\section{ACKNOWLEDGEMENTS}

This research was partly supported by a USC Open Learning and Teaching Grant (OLTGP2012/04). The authors also thank the reviewers and the Assistant Editor for suggestions that improved this paper.

\section{REFERENCES}

Aliaga, M., Cobb, G., Cuff, C., Garfield, J., Gould, R., Lock, R., Moore, T., Rossman, A., Stephenson, B., Utts, J., Velleman, P., \& Witmer, J. (2005). Guidelines for assessment and instruction in statistics education: College report. Alexandria, VA: American Statistical Association.

Anderson-Cook, C. M. (2010). Hidden jargon: Everyday words with meanings specific to statistics. In C. Reading (Ed.), Data and context in statistical education: Towards an evidence-based society. Proceedings of the Eighth International Conference on Teaching Statistics (ICOTS8), Ljubljana, Slovenia. Voorburg, The Netherlands: International Statistical Institute.

[Online: iase-web.org/documents/papers/icots8/ICOTS8_C202_ANDERSONCOOK.pdf]

Arnaud, P. J., \& Savignon, S. J. (1997). Rare words, complex lexical units and the advanced learner. In J. Coady \& T. Huckin (Eds.), Second language vocabulary acquisition, (pp. 157-173). Cambridge, UK: Cambridge University Press.

Aron, A., Aron, E. N., \& Coups, E. J. (2009). Statistics for psychology [international edition]. Upper Saddle River, NJ: Pearson Prentice Hall.

Australian Curriculum, Assessment and Reporting Authority (ACARA) (2014a). Essential Mathematics

[Online::www.australiancurriculum.edu.au/seniorsecondary/mathematics/essentialmathematics/curriculum/seniorsecondary\#page $=11$

Australian Curriculum, Assessment and Reporting Authority (ACARA) (2014b). General Mathematics

[Online: www.australiancurriculum.edu.au/seniorsecondary/mathematics/generalmathematics/curriculum/seniorsecondary\#page $=11$

Barwell, R. (2005). Ambiguity in the mathematics classroom. Language and Education, 19(2), 118-126.

Barwell, R., Leung, C., Morgan, C., \& Street, B. (2005). Applied linguistics and mathematics education: More than words and numbers. Language and Education, 19(2), 142-147.

Ben-Zvi, D. (2000). Toward understanding the role of technological tools in statistical learning. Mathematical Thinking and Learning, 2(1-2), 127-155.

Bock, D. E., Velleman, P. F., \& De Veaux, R. D. (2010). Stats: Modeling the world (3rd ed.). Boston, MA: Addison-Wesley.

Carlisle, J. F., Fleming, J. E., \& Gudbrandsen, B. (2000). Incidental word learning in science classes. Contemporary Educational Psychology, 25(2), 184-211.

Chance, B., Ben-Zvi, D., Garfield, J., \& Medina E. (2007). The role of technology in improving student learning of statistics. Technology Innovations in Statistics Education, 1(1), 1-26. 
Dossey, J. A., Otto, A. D., Spence, L. E., \& Vanden Eynden, C. (2002). Discrete mathematics. Boston, MA: Addison-Wesley.

Eisenhauer, J. G. (2008). Degrees of freedom. Teaching Statistics, 30(3), 75-78.

Ellis, N. C. (1994). Vocabulary acquisition: the implicit ins and outs of explicit cognitive mediation. In N. C. Ellis (Ed.), Implicit and explicit learning of languages (pp. 211282). London: Academic Press.

Everitt, B. S. (2006). The Cambridge dictionary of statistics (3rd ed.). New York: Cambridge University Press.

Flanagan-Hyde, P. (2005). Confound it! I can't keep these variables straight! STATS: The Magazine for Students of Statistics, 43, 21-23.

Fullerton, J. A., \& Umphrey, D. (2002). The decision to major in advertising: Gender differences and other factors. Southwestern Mass Communication Journal, 18(1), 3647.

Garfield, J. B., \& Ben-Zvi, D. (2008). Developing students' statistical reasoning: Connecting research and teaching practice. New York: Springer.

Gelman, A. (2005). Analysis of variance: Why it is more important than ever (with discussion). The Annals of Statistics, 33(1), 1-53.

Gordon, S. (1999, April). An instrument for exploring students' approaches to learning statistics. Paper presented at the Annual Meeting of the American Educational Research Association, Montreal, Quebec, Canada. (ERIC Document Reproduction Service No. ED 440142).

Guan, T. E., \& Hoong, L. Y. (2012). Explaining definitions in secondary school mathematics: $a^{0}, a^{n}, 0$ !. Australian Senior Mathematics Journal, 26(2), 28-37.

Issakova, M. (2006). Comparison of student errors made during linear equation solving on paper and in interactive learning environment. In J. Böhm (Ed.), Proceedings of the Dresden International Symposium on Technology and its Integration into Mathematics Education 2006, Dresden, Germany.

Jiang, N. (2000). Lexical representation and development in a second language. Applied Linguistics, 21(1), 47-77.

Johnson, R., \& Kuby, P. (2012). STAT (2nd ed.). Boston, MA: Cengage Learning.

Kaplan, J. J., Fisher, D. G., \& Rogness, N. T. (2009). Lexical ambiguity in statistics: what do students know about the words association, average, confidence, random and spread? Journal of Statistics Education, 17(3), 1-19.

[Online: www.amstat.org/publications/jse/v17n3/kaplan.pdf ]

Kaplan, J. J., Fisher, D. G., \& Rogness, N. T. (2010). Lexical ambiguity in statistics: how students use and define the words association, average, confidence, random and spread. Journal of Statistics Education, 18(2), 1-22.

[Online: www.amstat.org/publications/jse/v18n2/kaplan.pdf ]

Kaplan, J. J., Rogness, N. T., \& Fisher, D. G. (2012). Lexical ambiguity in statistics: Making a case against spread. Teaching Statistics, 34(2), 56-60.

Kaplan, J. J., Rogness, N. T., \& Fisher, D. G. (2014). Exploiting lexical ambiguity to help students understand the meaning of random. Statistical Education Research Journal, 13(1), 9-24.

[Online: iase-web.org/documents/SERJ/SERJ13(1)_Kaplan.pdf ]

Kreft, I., \& de Leeuw, J. (1998). Introducing multilevel modeling. London: Sage.

Kutas, M., \& Federmeier, K. D. (2000). Electrophysiology reveals semantic memory use in language comprehension. Trends in Cognitive Sciences, 4(12), 463-470.

Lavy, I., \& Mashiach-Eizenberg, M. (2009). The interplay between spoken language and informal definitions of statistical concepts. Journal of Statistics Education, 17(1), 1-9. [Online: www.amstat.org/publications/jse/v17n1/lavy.pdf ] 
Leavy, A. M., Hannigan, A., \& Fitzmaurice, O. (2013). If you're doubting yourself then, what's the fun in that? An exploration of why prospective secondary teachers perceive statistics as difficult. Journal of Statistics Education, 21(3), 1-26.

[Online: http://www.amstat.org/publications/jse/v21n3/leavy.pdf ]

Leung, C. (2005). Mathematical vocabulary: Fixers of knowledge or points of exploration? Language and Education, 19(2), 127-135.

MacGillivray, H., Utts, J., \& Heckard, R. F. (2014). Utts \& Heckard's Mind on statistics (2nd ed.). Melbourne, Australia: Cengage Learning Australia.

Marshman, M., Dunn, P., McDougall, R., \& Wiegand, A. (2015). A case study of the attitudes and preparedness of a group of secondary mathematics teachers towards statistics. Australian Senior Mathematics Journal, 29(1), 51-64.

Meara, P. (1978). Learners' word association in French. Interlanguage Studies Bulletin Utrecht, 3(2), 192-211.

Miller, J. E. (2008). The Chicago guide to writing about numbers. Chicago, IL: University of Chicago Press.

Moore, D. S., Notz, W. I., \& Fligner, M. A. (2015). The basic practice of statistics (7th ed.). New York: W. H. Freeman.

Onwuegbuzie, A. J. (2000). Statistics anxiety and the role of self-perceptions. Journal of Educational Research, 93(5), 323-330.

Petty, N. W. (2014). Nominal, ordinal, interval, schmordinal. Accessed November 20.

[Online: learnandteachstatistics.wordpress.com/2014/11/19/nominal-ordinal-intervalschmordinal/ ]

Pfenning, N. (2011). SPSS 17 technology guide for elementary statistics: Looking at the big picture. Boston, MA: Brooks/Cole.

Pinker, S. (1999). Words and rules: The ingredients of language. New York: Basic Books.

Pinker, S. (2014). The sense of style: The thinking person's guide to writing in the 21st century. New York, NY: Penguin.

Pitt, H. (1991). Statistical jargon spoken here! In 45th Annual Quality Congress Transactions (pp. 610-614). Milwaukee, WI: American Society for Quality.

$\mathrm{R}$ Core Team (2014). R: A language and environment for statistical computing. $\mathrm{R}$ Foundation for Statistical Computing, Vienna, Austria.

Retrieved from http://www.R-project.org/.

Rangecroft, M. (2002). The language of statistics. Teaching Statistics, 24(2), 34-37.

Richards, J. C., \& Schmidt, R. (2010). Longman dictionary of language teaching and applied linguistics ( $4^{\text {th }}$ ed.). Harlow, UK: Longman.

Richardson, A. M., Dunn, P. K., \& Hutchins, R. (2013a). Identification and definition of lexically ambiguous words in statistics by tutors and students. International Journal of Mathematical Education in Science and Technology, 44(7), 1007-1019.

Richardson, A. M., Dunn, P. K., \& Hutchins, R. (2013b). The impact of tutor, extract and word on the correct definition of lexically ambiguous words in statistics. In A. Yeung (Ed.), ACSME Proceedings: Students in transition - the learners' journey (pp. 185192). Sydney, Australia: UniServe Science, University of Sydney.

Rohrer, D., \& Taylor, K. (2006). The effects of overlearning and distributed practise on the retention of mathematics knowledge. Applied Cognitive Psychology, 20(9), 12091224.

Rumsey, D. J. (2002). Statistical literacy as a goal for introductory statistics courses. Journal of Statistics Education, 10(3).

[Online: http://www.amstat.org/publications/jse/v10n3/rumsey2.html]

Sanz, C., \& Morgan-Short, K. (2005). Explicitness in pedagogical interventions: Input, practice, and feedback. In C. Sanz (Ed.), Mind and context in adult second language 
acquisition: Methods, theory, and practice (pp. 234-263). Washington, DC: Georgetown University Press.

Schmitt, N. (1998). Quantifying word association responses: What is native-like? System, 26(3), 389-401.

Schmitt, N., \& Meara, P. (1997). Researching vocabulary through a word knowledge framework. Word association and verb suffixes. Studies in Second Language Acquisition, 19(1), 17-36.

Schmitt, N. (2007). Current perspectives on vocabulary teaching and learning. In J. Cummins \& C. Davison (Eds.), International handbook of English language teaching (pp. 827-841). New York: Springer.

Schmitt, N. (2008). Instructed second language vocabulary learning. Language Teaching Research, 12(3), 329-363.

Shuard, H., \& Rothery, A. (Eds.) (1984). Children reading mathematics. London: John Murray.

Sullivan, M. (2010). Statistics: Informed decisions using data. Upper Saddle River, NJ: Pearson.

Summers, J. J., Waigandt, A., \& Whittaker, T. A. (2005). A comparison of student achievement and satisfaction in an online versus a traditional face-to-face statistics class. Innovative Higher Education, 29(3), 233-250.

Sutarso, T. (1992, November). Some variables in relation to students' anxiety in learning statistics. Paper presented at the Annual Meeting of the Mid-South Educational Research Association. (ERIC Document Reproduction Service No. ED 353316).

Thompson, D. R., \& Rubenstein, R. N. (2000). Learning mathematics vocabulary: Potential pitfalls and instructional strategies. The Mathematics Teacher, 93(7), 568-574.

Utts, J., \& Heckard, R. F. (2015). Mind on statistics (5th ed.). Stamford, CT: Duxbury Thomson Learning.

Wild, C. J., \& Seber, G. A. F. (2000). Chance encounters: A first course in data analysis and inference. New York: John Wiley \& Sons.

Willcoxson, L., Cotter, J., \& Joy, S. (2011). Beyond the first-year experience: the impact on attrition of student experiences throughout undergraduate degree studies in six diverse universities. Studies in Higher Education, 36(3), 331-352.

Willis, D., \& Willis, J. (2007). Doing task-based teaching. Oxford, UK: Oxford University Press.

Wood, L. (1990). Teaching statistics to students from a non-English speaking background. In D. Vere-Jones (Ed.), Proceedings of the 3rd International Conference on Teaching Statistics, Dunedin, New Zealand (pp. 291-297). Voorburg, The Netherlands: International Statistical Institute.

[Online: http://iase-web.org/documents/papers/icots3/BOOK1/A5-8.pdf ]

Zhang, S. (2003). Cong FanYing LeiXing Kan CiHui XiDe [Response types and lexical acquisition]. WaiYu JiaoXue Yu YanJiu [Foreign Language Teaching and Research], 4, 275-281.

Zieffler, A., \& Catalysts for Change (2013). Statistical thinking: A simulation approach to uncertainty (2nd ed.). Minneapolis, MN: Catalyst Press.

PETER K. DUNN

Faculty of Science, Health, Education and Engineering

University of the Sunshine Coast

Sippy Downs, Queensland, 4556

AUSTRALIA 